\title{
Is it the resistance training itself or the combined associated weight loss that improves the metabolic syndrome-related phenotypes in postmenopausal women?
}

\author{
This article was published in the following Dove Press journal: \\ Clinical Interventions in Aging \\ 16 October 2015 \\ Number of times this article has been viewed
}

\author{
Ozlem Soyluk' \\ Gulistan Bahat ${ }^{2}$ \\ 'Division of Endocrinology and \\ Metabolism, Department of Internal \\ Medicine, Istanbul Medical School, \\ Istanbul University, Capa, Istanbul, \\ Turkey; ${ }^{2}$ Division of Geriatrics, \\ Department of Internal Medicine, \\ Istanbul Medical School, Istanbul \\ University, Capa, Istanbul, Turkey
}

Correspondence: Gulistan Bahat Division of Geriatrics, Department of Internal Medicine, Istanbul Medical School, Istanbul University, Capa, 34390, Istanbul, Turkey Tel +902124142000 ext 33204 Fax +902125324208 Email gbahatozturk@yahoo.com

\section{Dear editor}

We read the article entitled "Resistance training improves isokinetic strength and metabolic syndrome-related phenotypes in postmenopausal women" by Oliveira et $\mathrm{al}^{1}$ with great interest. In the study, the authors examined the effects of 12 weeks of resistance training (RT) on metabolic syndrome-related phenotypes in postmenopausal women. They reported that total cholesterol, low-density lipoprotein cholesterol levels, total cholesterol/high-density lipoprotein cholesterol ratio, blood glucose, basal insulin, and homeostatic model assessment of insulin resistance were all significantly reduced with RT $(P<0.01)$. Accordingly, they concluded that a 12-week progressive RT program induces beneficial alterations on metabolic syndrome-related phenotypes in postmenopausal women.

While we appreciate this detailed study, ${ }^{1}$ we have some comments on the results and subsequent conclusions. In their study, Oliveira et al reported that, in addition to the aforementioned parameters (indices), body mass $(68.9 \pm 13.3 \mathrm{~kg}$ before RT vs $68.1 \pm 13.2 \mathrm{~kg}$ after 12 weeks' RT), body mass index (BMI) $\left(28.4 \pm 5.0 \mathrm{~kg} / \mathrm{m}^{2}\right.$ before RT vs $27.9 \pm 4.8 \mathrm{~kg} / \mathrm{m}^{2}$ after 12 weeks' RT), and waist circumference (WC) $(98.3 \pm 13.2 \mathrm{~cm}$ before RT vs $94.6 \pm 12.6 \mathrm{~cm}$ after 12 weeks' RT) were also significantly decreased after the RT period. ${ }^{1}$

Increased body weight is a very well-known major risk factor for the metabolic syndrome documented both in cross-sectional and longitudinal studies. ${ }^{2,3}$ Obesity, particularly abdominal obesity, is associated with insulin resistance. Furthermore, the importance of weight management in preventing progression of metabolic syndrome components has also already been illustrated. ${ }^{4}$ Hence, we suggest that the reported association of RT with beneficial alterations on metabolic syndrome-related phenotypes may be due to the combined weight, BMI, and WC reduction, rather than the effect of RT itself.

In line with our comment, in the study aimed at addressing whether RT alone improves cardiometabolic health in overweight and obese adults, Bateman et $\mathrm{al}^{5}$ concluded that RT was not effective at improving the metabolic syndrome score; however, aerobic training (AT) was effective. Combined AT and RT was similarly effective but not different from AT alone. Importantly, in this study, body mass was significantly decreased with AT and combined AT-RT, but was not changed with RT alone. ${ }^{5}$ In a similar study aiming to clarify effects of exercise modality on insulin resistance, Davidson et $\mathrm{al}^{6}$ also reported that insulin resistance improved compared with controls 
with aerobic exercise alone and in the combined exercise groups, but not in the resistance exercise group. Again, in this later study, body weight was not significantly reduced in the resistance exercise group. ${ }^{6}$ On the other hand, Dunstan et al ${ }^{7}$ reported that high-intensity progressive RT was effective in improving glycemic control in older patients with type 2 diabetes when combined with moderate weight loss.

The results of these studies ${ }^{5-7}$ suggest that RT seems not to affect the metabolic syndrome parameters if not accompanied with weight, BMI, or WC reduction. Therefore, we suggest that in the Oliveira et al ${ }^{1}$ study, RT and weight loss should be analyzed with regression analysis for their relation to metabolic syndrome parameters in order to clarify whether RT itself is independently associated with metabolic syndrome.

\section{Disclosure}

The authors report no conflicts of interest in this communication.

\section{References}

1. Oliveira PF, Gadelha AB, Gauche R, et al. Resistance training improves isokinetic strength and metabolic syndrome-related phenotypes in postmenopausal women. Clin Interv Aging. 2015;10:1299-1304.

2. Park YW, Zhu S, Palaniappan L, Heshka S, Carnethon MR, Heymsfield SB. The metabolic syndrome: prevalence and associated risk factor findings in the US population from the Third National Health and Nutrition Examination Survey, 1988-1994. Arch Intern Med. 2003;163(4):427-36.

3. Wilson PW, Kannel WB, Silbershatz H, D'Agostino RB. Clustering of metabolic factors and coronary heart disease. Arch Intern Med. 1999;159(10):1104-1109.

4. Lloyd-Jones DM, Liu K, Colangelo LA, et al. Consistently stable or decreased body mass index in young adulthood and longitudinal changes in metabolic syndrome components: the Coronary Artery Risk Development in Young Adults Study. Circulation. 2007;115(8):1004-1011.

5. Bateman LA, Slentz CA, Willis LH, et al. Comparison of aerobic versus resistance exercise training effects on metabolic syndrome (from the studies of a Targeted Risk Reduction Intervention Through Defined Exercise - STRRIDE-AT/RT). Am J Cardiol. 2011;108(6):838-844.

6. Davidson LE, Hudson R, Kilpatrick K, et al. Effects of exercise modality on insulin resistance and functional limitation in older adults: a randomized controlled trial. Arch Intern Med. 2009;169(2):122-131.

7. Dunstan DW, Daly RM, Owen N, et al. High-intensity resistance training improves glycemic control in older patients with type 2 diabetes. Diabetes Care. 2002;25(10):1729-1736. 


\section{Author's reply}

Ricardo Moreno Lima

André Bonadias Gadelha

Lauro C Vianna

College of Physical Education, University of Brasília, Brasília, Federal District, Brazil

Correspondence: Ricardo Moreno Lima

Universidade de Brasília (UnB), Campus Universitário Darcy Ribeiro,

Faculdade de Educação Física, Brasília, Distrito Federal, Brazil

Tel +55 6I 81099444

$\mathrm{Fax}+556131072500$

Email ricardomoreno@unb.br

\section{Dear editor}

We are enthusiastic that our study has earned the attention of others, and we are pleased to have the opportunity to further debate the merits of our findings. Soyluk and Bahat's letter to the editor ${ }^{1}$ raises some interesting insights regarding the interpretation of our results, in particular, whether or not resistance training (RT) independently ameliorates metabolic syndrome-related phenotypes in postmenopausal women. We would like to address the perceptions of these authors and are confident that such discussion will be valuable for health professionals designing clinical interventions for older adults.

In our study, ${ }^{2}$ we demonstrated that a 12 -week RT program induces beneficial alterations on metabolic syndromerelated phenotypes in postmenopausal women. The benefits were related to waist circumference (WC) reduction, positive alterations on lipid profile, and improvements in glycemic control. The letter to the editor ${ }^{1}$ suggests that the observed alterations on metabolic profile may be due to weight, body mass index (BMI), and WC decreases, rather than to the effect of RT itself. In this regard, it should be noted that although body weight and BMI reached borderline significance, these reductions were modest (from $68.9 \pm 13.3 \mathrm{~kg}$ to $68.1 \pm 13.2 \mathrm{~kg}$, and from $28.4 \pm 5.0 \mathrm{~kg} / \mathrm{m}^{2}$ to $27.9 \pm 4.8 \mathrm{~kg} / \mathrm{m}^{2}$, respectively), and with small effect sizes ( 0.05 and 0.09 , respectively), while the reduction in $\mathrm{WC}$ was more compelling $(P<0.001)$ and with larger effect size (from $98.3 \pm 13.2 \mathrm{~cm}$ to $94.6 \pm 12.6$ $\mathrm{cm}$; effect size $=0.30$ ). WC is consistently related to cardiometabolic risk ${ }^{3}$ and is a pivotal criterion for metabolic syndrome definition. ${ }^{4,5}$ Thus, the RT protocol induced a decrease in WC, which per se is a metabolic syndrome-related phenotype. This observation is in agreement with previous RT studies in older individuals. ${ }^{6-8}$

The points raised in the letter, however, lead to an important question: were changes observed for metabolic profile related to changes in WC? Furthermore, Soyluk and Bahat ${ }^{1}$ suggested regression analyses to address this question, and we are thankful for that suggestion. As such, we performed the regression analyses, and the results did not show significance, with only a trend for the relationship between $\triangle \mathrm{WC}$ and $\Delta$ total cholesterol $\left(r=0.31 ; r^{2}=0.09 ; P=0.08\right)$ evident. Certainly, these results do not rule out the possibility of RT-induced visceral fat decrease to partially explain metabolic improvements.

Despite this result, the positive metabolic effects of exercise in general, and RT in particular, should also be considered in light of other underlying physiological mechanisms. A consistent body of evidence ${ }^{9,10}$ indicates that physical inactivity is causative in the development of metabolic diseases. In animal models, cessation of voluntary physical activity precipitated a rapid (just 24 hours) decline in insulin-mediated glucose uptake that was paralleled by a reduction in molecular signaling pathways related to the insulin receptor and its activation. ${ }^{11}$ These observations confirm the rapid decline in insulin sensitivity when physically active humans discontinue regular exercise. ${ }^{12}$ Conversely, only 7 days of exercise training were sufficient to significantly improve glycemic control in sedentary, middle-aged individuals. ${ }^{13}$ In regard to resistance exercises, Singhal et al ${ }^{14}$ noted that different training intensities acutely induce reductions in postprandial lipemia, lessening exposure to elevated atherogenic low-density lipoprotein cholesterol levels. These findings highlight how metabolic variables can be rapidly affected by both physical activity and inactivity, without alterations in body fat. In support of this idea, Poehlman et $\mathrm{al}^{15}$ demonstrated metabolic improvements as a result of RT that occurred without alterations in total body fat, subcutaneous tissue, or visceral adipose tissue. Importantly, these findings have been recapitulated by other groups. ${ }^{16,17}$ Taken together, the results of these studies provide evidence that, in addition to weight loss, other mechanisms might contribute to metabolic improvements following RT.

In summary, the results of our study ${ }^{2}$ show that RT improves metabolic syndrome-related phenotypes in postmenopausal women, and thus, these results have important clinical implications. It was not in the scope of the study to examine the mechanisms underlying such alterations. Soyluk and Bahat's letter to the editor ${ }^{1}$ raised the interesting question of whether RT per se, or its combination with weight loss, explained metabolic improvements. They suggested regression analyses to examine such a question, which we performed, but the results did not reveal significant association. A plethora of studies indicate that although weight loss is important, other mechanisms are likely to contribute 
to RT-induced metabolic improvements. Nevertheless, it is reasonable to suggest that the positive effects of RT on metabolic traits would be extended if associated with reduction in body weight, particularly visceral fat. In any case, the "take-home" message from our study remains the same: RT should be considered in the prevention of metabolic syndrome, and our results ${ }^{2}$ reinforce the idea that this mode of exercise is an important component of physical activity programs for elderly people.

\section{Disclosure}

The authors report no conflicts of interest in this communication.

\section{References}

1. Soyluk O, Bahat G. Is it the resistance training itself or the combined associated weight loss improving the metabolic sydrome-related phenotypes in postmenopausal women? Clin Interv Aging. 2015.

2. Oliveira PFA, Gadelha AB, Gauche R, et al. Resistance training improves isokinetic strength and metabolic syndrome-related phenotypes in postmenopausal women. Clin Interv Aging. 2015;10:1299-1304.

3. dos Santos EP, Gadelha AB, Safons MP, Nóbrega OT, Oliveira RJ, Lima RM. Sarcopenia and sarcopenic obesity classifications and cardiometabolic risks in older women. Arch Gerontol Geriatr. 2014;59(1): 56-61.

4. Expert Panel on Detection, Evaluation, and Treatment of High Blood Cholesterol in Adults. Executive summary of the third report of the National Cholesterol Education Program (NCEP) expert panel on detection, evaluation, and treatment of high blood cholesterol in adults (Adult Treatment Panel III). JAMA. 2001;285(19):2486-2497.

5. Kassi E, Pervanidou P, Kaltsas G, Chrousos G. Metabolic syndrome: definitions and controversies. BMC Med. 2011;9:48.

6. Rabelo HT, Bezerra LA, Terra DF, et al. Effects of 24 weeks of progressive resistance training on knee extensors peak torque and fat-free mass in older women. J Strength Cond Res. 2011;25(8):2298-2303.
7. Misra A, Alappan NK, Vikram NK, et al. Effect of supervised progressive resistance-exercise training protocol on insulin sensitivity, glycemia, lipids, and body composition in Asian Indians with type 2 diabetes. Diabetes Care. 2008;31(7):1282-1287.

8. Leenders M, Verdijk LB, van der Hoeven L, van Kranenburg J, Nilwik R, van Loon LJ. Elderly men and women benefit equally from prolonged resistance-type exercise training. J Gerontol A Biol Sci Med Sci. 2013;68(7):769-779.

9. Bergouignan A, Rudwill F, Simon C, Blanc S. Physical inactivity as the culprit of metabolic inflexibility: evidence from bed-rest studies. J Appl Physiol (1985). 2011;111(4):1201-1210.

10. Booth FW, Laye MJ, Lees SJ, Rector RS, Thyfault JP. Reduced physical activity and risk of chronic disease: the biology behind the consequences. Eur J Appl Physiol. 2008;102(4):381-390.

11. Kump DS, Booth FW. Alterations in insulin receptor signalling in the rat epitrochlearis muscle upon cessation of voluntary exercise. $J$ Physiol. 2005;562(Pt 3):829-838.

12. Burstein R, Polychronakos C, Toews CJ, MacDougall JD, Guyda H, Posner BI. Acute reversal of the enhanced insulin action in trained athletes. Association with insulin receptor changes. Diabetes. 1985; 34(8):756-760.

13. Mikus CR, Fairfax ST, Libla JL, et al. Seven days of aerobic exercise training improves conduit artery blood flow following glucose ingestion in patients with type 2 diabetes. J Appl Physiol (1985). 2011;111(3): 657-664.

14. Singhal A, Trilk JL, Jenkins NT, Bigelman KA, Cureton KJ. Effect of intensity of resistance exercise on postprandial lipemia. $J$ Appl Physiol (1985). 2009;106(3):823-829.

15. Poehlman ET, Dvorak RV, DeNino WF, Brochu M, Ades PA. Effects of resistance training and endurance training on insulin sensitivity in nonobese, young women: a controlled randomized trial. J Clin Endocrinol Metab. 2000;85(7):2463-2468.

16. Duncan GE, Perri MG, Theriaque DW, Hutson AD, Eckel RH, Stacpoole PW. Exercise training, without weight loss, increases insulin sensitivity and postheparin plasma lipase activity in previously sedentary adults. Diabetes Care. 2003;26(3):557-562.

17. Zachwieja JJ, Toffolo G, Cobelli C, Bier DM, Yarasheski KE. Resistance exercise and growth hormone administration in older men: effects on insulin sensitivity and secretion during a stable-label intravenous glucose tolerance test. Metabolism. 1996;45(2):254-260.

Dove Medical Press encourages responsible, free and frank academic debate. The content of the Clinical Interventions in Aging 'letters to the editor' section does not necessarily represent the views of Dove Medical Press, its officers, agents, employees, related entities or the Clinical Interventions in Aging editors. While all reasonable steps have been taken to confirm the content of each letter, Dove Medical Press accepts no liability in respect of the content of any letter, nor is it responsible for the content and accuracy of any letter to the editor.

\section{Publish your work in this journal}

Clinical Interventions in Aging is an international, peer-reviewed journal focusing on evidence-based reports on the value or lack thereof of treatments intended to prevent or delay the onset of maladaptive correlates of aging in human beings. This journal is indexed on PubMed Central, MedLine,
CAS, Scopus and the Elsevier Bibliographic databases. The manuscript management system is completely online and includes a very quick and fair peer-review system, which is all easy to use. Visit http://www.dovepress. com/testimonials.php to read real quotes from published authors. 